\title{
A double blind controlled trial of methylprednisolone infusions in systemic lupus erythematosus using individualised outcome assessment
}

\author{
J C W EDWARDS, M L SNAITH, AND D A ISENBERG \\ From the Department of Rheumatology, University College Hospital, London
}

SUMMARY Twenty one patients with severe systemic lupus erythematosus (SLE) were treated with three daily infusions of either $100 \mathrm{mg}$ or $1 \mathrm{~g}$ of methylprednisolone on a randomised double blind basis. Nine patients with unsatisfactory outcome subsequently received the alternative therapy. Patients were rated for improvement on a four point scale using individualised criteria. On three occasions patients improved to 'ideal', on 12 there was 'useful' improvement, on 11 the patient remained static, and on four occasions there was deterioration. There was no significant difference between the clinical states after the two doses. The results suggest that any additional benefit of $1 \mathrm{~g}$ of methylprednisolone over $100 \mathrm{mg}$ by repeated infusion in the treatment of active SLE is probably not enough to justify the potential hazards and cost involved.

The use of repeated daily infusions of $1 \mathrm{~g}$ of methylprednisolone has become a popular treatment for severe systemic lupus erythematosus (SLE) ${ }^{1-4}$ It is thought to be of particular value for thrombocytopenia $^{5}$ and diffuse proliferative glomerulonephritis. ${ }^{6}$ Some physicians may restrict its use to these indications, but our previous experience was that a wide range of disease manifestations responded usefully. High dose infusions have also been used in rheumatoid arthritis, polymyositis, ${ }^{8}$ and polyarteritis nodosa. ${ }^{9}$ The advantage of $1 \mathrm{~g}$ doses over more traditional doses (up to $100 \mathrm{mg}$ prednisolone per day) remained unproved.

Methylprednisolone infusion carries potential hazards, such as predisposition to infection and acute gastrointestinal haemorrhage, ${ }^{10}$ and requires costly admission to hospital. In addition, anaphylaxis, ${ }^{11}$ seizures,${ }^{12}$ cardiac arrhythmias,${ }^{13}$ and sudden death ${ }^{14}$ have all been described in association. We have used infusions given slowly over a four hour period ${ }^{15}$ and concomitant histamine $\left(\mathrm{H}_{2}\right)$ antagonist therapy and thus avoided major complications. The purpose of the present trial was to establish whether or not this form of treatment had

Accepted for publication 1 May 1987.

Correspondence to Dr J C W Edwards. Department of Rhcumatology, University College Hospital, Gower Street, London WC1E 6AU. sufficient added benefit, over and above that achieved by treatment with doses of steroid up to $100 \mathrm{mg}$ prednisolone equivalent, to justify its continued use.

\section{Patients and methods}

PATIENTS

Patients entering the trial were either regular attenders at the SLE clinic at University College Hospital or new referrals admitted to the ward. All patients met four of the revised American Rheumatism Association criteria for SLE. ${ }^{16}$ Ages ranged from 19 to 61 years. Twenty patients were female and one male.

Patients entered the trial on the basis of either severity or failure of clinical features of SLE to respond to simpler measures. Broadly speaking, patients who entered on the basis of severity were febrile without evidence of infection or had cerebral or renal problems. Other patients had failed to respond to chloroquine or doses of oral prednisolone up to $15 \mathrm{mg}$ daily. A detailed description of the clinical features and treatment schedules of patients at the time of entry is given in Table 1 . All patients had overt clinical features of SLE at entry, although patient 8 had acute onset of malaise, shortness of breath, and an erythrocyte sedimentation rate above $100 \mathrm{~mm} / \mathrm{h}$ as her only major features. 
Each patient was randomly allocated to treatment with methylprednisolone intravenously either at a dose of $100 \mathrm{mg}$ daily for three days or $1 \mathrm{~g}$ daily for three days. Nine patients also subsequently received the alternative dosage (see below, 'Alternative dosage'). Neither the patient nor the physicians administering and assessing treatment were aware of which dose had been given.

\section{ENTRY PROCEDURE}

On entry, a set of criteria was laid down for each patient on the basis of their clinical state at entry, indicating what would be considered 'ideal' improvement, 'useful' improvement, no change, and deterioration.

Ideal improvement was intended to indicate the best possible outcome which might be expected in the face of any irreversible problems such as joint deformity or chronic uraemia, sustained for at least three months.

Useful improvement was intended to indicate an improvement short of ideal which justified the cost, inconvenience, and potential hazard of high dose steroid infusion, and which was sustained for at leas three months.

A static state was intended to indicate the absence of either useful improvement or significant de terioration, assessed at three months, or earlier if withdrawn for alternative dosage treatment.

Significant deterioration was intended to imply that clinical problems had worsened or that nevo problems had developed which were of greate importance than any coexisting improvement. The appearance of renal disease in the face of improve $\vec{D}$ arthralgia would be considered deterioration, but the development of arthralgia in the face of signifi cant improvement in renal function would not? Assessment was made at three months, or earlier if withdrawn for alternative dosage treatment.

The criteria for outcome were different for eact $\vec{\delta}$ patient, based on the problems of relevance to that individual. Criteria were often quite complex, being derived from a range of baseline clinical and laboratory data. An example of a set of criteria is given in Table 2. Full details of every individual' criteria are available from the authors.

Table 1 Clinical features and prednisolone dosage for patients on entry

\begin{tabular}{|c|c|c|c|c|c|c|c|c|c|}
\hline $\begin{array}{l}\text { Patient } \\
\text { No }\end{array}$ & Fever & Rash & Nephritis & Serositis & Arthralgia & Haematolog. & Cerebral & Lymphadenopathy & $\begin{array}{l}\text { Prednisolone } \\
\text { (mg/day) }\end{array}$ \\
\hline $1(\mathrm{i})$ & + & + & & & & & + & & 5 \\
\hline (ii) & + & + & & & & & + & & 0 \\
\hline 2(i) & & + & & & + & & & & 0 \\
\hline (ii) & & + & & & + & & & & 0 \\
\hline $3(\mathrm{i})$ & + & + & & & + & & & & 15 \\
\hline (ii) & + & + & & & + & & & & 15 \\
\hline $4(\mathrm{i})$ & & & + & & + & & & & 5 \\
\hline $5(\mathrm{i})$ & & & + & + & & + & & & 7 \\
\hline 6(i) & & & & & + & & & & 5 \\
\hline $7(\mathrm{i})$ & & + & & + & + & & + & & 12.5 \\
\hline $8(\mathrm{i})$ & & & & & & & & & 0 \\
\hline $9(\mathrm{i})$ & & & & & + & & & & 15 \\
\hline (ii) & & & & & + & & & & 10 \\
\hline $10(\mathrm{i})$ & + & & + & + & & + & & & 0 \\
\hline (ii) & + & & + & + & & + & + & & 0 \\
\hline $11(\mathrm{i})$ & + & & & + & + & & & & 15 \\
\hline (ii) & + & & & + & + & & & & 15 \\
\hline $12(\mathrm{i})$ & & & & + & + & & + & & 15 \\
\hline (ii) & & & & + & + & & + & & 10 \\
\hline 13(i) & & & + & & & + & & & 12.5 \\
\hline 14(i) & & + & & + & & & & & 15 \\
\hline $15(\mathrm{i})$ & & + & & + & + & & & & 10 \\
\hline (ii) & & + & & + & + & & & & 10 \\
\hline $16(i)$ & + & & & + & + & & & & 15 \\
\hline (ii) & + & & & + & & & & + & $12 \cdot 5$ \\
\hline $17(\mathrm{i})$ & & & + & & & & & + & 0 \\
\hline $\begin{array}{l}18(i) \\
19(i)\end{array}$ & & & & & + & & & + & $\begin{array}{l}0 \\
0\end{array}$ \\
\hline $\begin{array}{l}19(\mathrm{i}) \\
20(\mathrm{i})\end{array}$ & + & & & + & + & + & & & 0 \\
\hline 21 (i) & + & & & + & + & & & & 5 \\
\hline
\end{tabular}


Table 2 Criteria for patient 10 (first arm)

Clinical features on entry: pyrexia, leucopenia, anaemia, pleural effusion, pleuritic pain, and proteinuria.

Deterioration = Death. or cerebral disease. or proteinuria more than $8 \mathrm{~g} /$ day, or increase in plcural effusion on radiography. or neutrophil count below $10^{4} / 1$.

Static $=$ Neither 'deterioration' nor 'useful improvement'.

Useful improvement $=$ At least two of the following at three months: no pyrexia, proteinuria less than $1 \mathrm{~g} /$ day. $80 \%$ resolution of pleural effusion on radiography. neutrophil count above $2.5 \times 10^{9} / 1$ on two separate occasions.

Ideal=No features of SLE, and specifically, all criteria for useful improvement fulfilled and haemoglobin greater than $110 \mathrm{~g} / \mathrm{l}$ at three months without transfusion.

\section{A L TERNATIVE DOSAGE}

For ethical reasons we wished to ensure that all patients had the opportunity of receiving the higher dose of methylprednisolone during an acute exacerbation. To achieve this without breaking the randomisation code we allowed patients who had not responded satisfactorily to the first set of infusions to receive a second set of infusions at the alternative dose. Alternative dose treatment did not constitute a crossover as such, and was analysed separately.

A patient could be retreated with the alternative dose if the following criteria were met: $(a)$ if significant deterioration had occurred and at least three days had elapsed since the last infusion of the first dose had been given, or $(b)$ if the patient remained clinically static and at least 14 days had elapsed since the last infusion of the first dose had been given, or $(c)$ three months had elapsed since the last infusion of the first dose had been given, and improvement was not satisfactorily maintained.

TREATMENT SCHEDULE

Methylprednisolone was made up in $500 \mathrm{ml}$ of normal saline or dextrose saline and infused over

Table 3 Outcome after methylprednisolone infusions

\begin{tabular}{lllll}
\hline Initial dose & Ideal & Useful & Static & Worse \\
\hline $1 \mathrm{~g}$ & 2 & 3 & 4 & 2 \\
$100 \mathrm{mg}$ & 1 & 5 & 2 & 2 \\
Alternative dose & & & & \\
$1 \mathrm{~g}$ & 2 & 3 & \\
$100 \mathrm{mg}$ & & 2 & 2 & \\
\hline
\end{tabular}

four hours. The same dose was added to each of three infusions, the infusions being given daily. The dose of methylprednisolone was known only to the hospital pharmarist. The initial dose for each patient was determined using randomisation tables. During the three days of treatment and for a further three days cimetidine was given at a total daily dose of $1 \mathrm{~g}$ in divided doses. Other forms of treatment were continued during the study period. Oral prednisolone was withdrawn during the days of the infusions and was reintroduced at a lower dose if necessary. No specific rules about use of other drugs were applied to the group as a whole, but in many cases the requirement for orál prednisolone or immunosuppressive drugs was included in the basis for criteria of outcome. Thus an ideal outcome might stipulate no oral steroid requirement at three months, but a useful improvement might be consistent with continued use of prednisolone where this represented a useful reduction in average daily dose.

\section{STATISTICAL ANALYSIS}

The study was designed for an entry of 20 patients. In the event 21 entries were made before the randomisation code was broken. A decision was made to restrict statistical analysis to a single overall comparison of outcomes in the two dosage groups using a contingency table technique. This was made possible by the use of individualised criteria of outcome.

\section{Results}

Unwanted effects attributable to methylprednisolone were few. No gastrointestinal bleeding occurred. (Massive bleeding had been experienced on one occasion previously using $1 \mathrm{~g}$ doses in a patient with rheumatoid arthritis with a previous history of duodenal ulceration.) No osteonecrosis occurred. Blood pressure rose temporarily in some patients but did not require treatment other than bed rest. Headache, mood swings, and other non-specific symptoms did not cause significant distress, and no patient refused repeated treatment on the basis of unwanted effects. Plasma urea levels rose in many cases, as did creatinine levels in a smaller proportion, but these returned to pretreatment levels within two weeks. Raised serum glucose levels were transient and not associated with symptoms.

Of the 21 treatment courses given at the initial dose, three were associated with ideal improvement, eight with useful improvement, six with no change, and four with significant deterioration. The details of these outcomes are given in Table 3. The outcomes associated with $1 \mathrm{~g}$ were slightly worse than those with $100 \mathrm{mg}$, so there was no question of 
a statistically significant benefit from the higher dose.

After the alternative dosage four patients showed useful improvement (two at each dose) and five were static (three at $1 \mathrm{~g}$ and two at $100 \mathrm{mg}$ ).

When improvement occurred there was, as a rule, rapid and dramatic relief of symptoms within a few days, as might be expected from high dose steroid.

\section{Discussion}

The results of this study suggest that although about half of patients with severe episodes of SLE treated with infusions of methylprednisolone may be expected to show improvement at three months, three doses of $1 \mathrm{~g}$ do not appear to have any advantage over three of $100 \mathrm{mg}$. The study fails to support the idea of a specific action of very high dose steroid in the treatment of severe episodes of SLE.

The trial was designed purely to answer a question about management of end organ problems in SLE and not to provide information about the disease process. In this context the over-riding aim was to extract the most powerful statistical information possible from heterogeneous data. Ideally, one would like to study large homogeneous groups with similar end organ problems, but it is unlikely that this can be achieved.

In trying to answer a question of outcome, the power of the statistical analysis is reduced in proportion to the number of analyses made which relate to the question. When dealing with very small numbers the only option is to use one outcome measure. A point scoring system using a range of clinical data which provided a sensitive reflection of each patient's problems would have to be based on an unmanageable set of rules involving many inter-related contingencies, involving time relationships and subtle grades of severity.

As an alternative we used a system of individualised criteria. This is equally valid statistically and can be much more closely tailored to events of importance to each patient. It suffers from the disadvantage that one physician's assessment of important outcome events may differ from another's. It became clear during the trial, however, that the two or three physicians drawing up each set of criteria agreed very closely on what constituted ideal improvement and useful improvement as originally defined. The study shows that it is feasible to conduct double blind trials using individualise outcome criteria.

Even with the use of individualised outcome: criteria the power of the statistical analysis is weaks because of small numbers. The study may not have detected a modest difference in effect between the two dosages, demonstrating the almost insuperable problems of studying uncommon heterogeneou\& disease. Nevertheless, we consider that indio vidualisation of outcome criteria goes part of the way to solving this problem and can be a ver 9 valuable technique.

\section{References}

1 Cathcart E S, Idelson B A, Scheiberg M A. Couser W G Beneficial effects of methylprednisolone 'pulse' therapy i\$ diffuse proliferative lupus nephritis. Lancet 1976; i: 163-6. $\overrightarrow{0}$

2 Dosa S, Cairns S A, Lawler W, Mallick N P, Slotki I N. The treatment of lupus nephritis by methylprednisolone puls\& therapy. Postgrad Med J 1978; 54: 628-32.

3 Evanson S, Passe M H, Aldo-Benson M A. Benson M D? Methylprednisolone pulse therapy for non-renal lupus erythematosus. Ann Rheum Dis 1980; 39: 377-80.

4 Isenberg D A, Morrow W J W, Snaith M L. Methylprednisolone pulse therapy in the treatment of systemic lupus erythematosu? Ann Rheum Dis 1982; 41: 347-51.

5 Lurie C. Kahaleh $M$ B. Pulse corticosteroid therapy for refractory thrombocytopenia in systemic lupus crythematos $\mathbb{S}_{\text {. }} \cdot \vec{b}$ Rheumatol 1982; 9: 311-4.

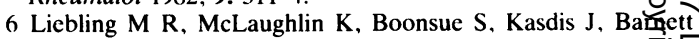
E V. Monthly pulses of methylprednisolone in SLE nepkșiji $J$ Rheumatol 1982; 9: 543-8.

7 Liebling M R, Leib E, McLaughlin K, et al. Pulse methylpred nisolone in rheumatoid arthritis. Ann Intern Med 1981; 94: 21-\%

8 Fessel W J. Megadose corticosteroid therapy in systemic lupto erythematosus. J Rheumatol 1980; 7: 486-500.

9 Neild G H, Lee H A. Methylprednisolone pulse therapy in the treatment of polyarteritis nodosa. Postgrad Med J 1977; 589 382-7.

10 Garrett R, Paulus H. Complications of intravenous methylpređ nisolone pulse therapy [Abstract]. Arthritis Rheum 1980; 28 677.

11 Freedman M D, Schocket A L, Chapel N, Gerber J बఖ Anaphylaxis after intravenous methylprednisolone administr tion. JAMA 1981; 245: 607-8.

12 Suchman A L, Condemi J J, Leddy J P. Seizure after pulș. therapy with methylprednisolone. Arthritis Rheum 1983;28 117.

13 Moses R E, McCormick A, Nickey W. Fatal arrhythmia aftêr pulse methylprednisolone. Ann Intern Med 1981; 95: 781-2. 익

14 Bocanegra T S, Castaneda M O, Espinoza L R, Vasey F B Germain B F. Sudden death after methylprednisolone puls therapy. Ann Intern Med 1981; 95: 122.

15 Newmark K J, Mitra S, Berman L B. Acute arthralgia following high dose intravenous methylprednisolone therapy. Lancet 1974; ii: 229.

16 Tan E M, Cohen A S, Fries J F, et al. The 1982 revised criten for the classification of systemic lupus erythematosus. Arthrites Rheum 1982; 25: 1271-7. 